\title{
RECIPROCIDAD Y UTILIDAD COMÚN EN LA FILOSOFÍA POLÍTICA DE SPINOZA
}

\author{
Aurelio Sainz Pezonaga \\ https://orcid.org/0000-0003-2978-9167 \\ Universidad de Castilla-La Mancha \\ https://doi.org/10.15304/ag.40.1.6687
}

\section{Resumen}

El artículo analiza la relación entre potencia, utilidad y derecho en la filosofía política de Spinoza. Explica la utilidad a partir del carácter relacional de la existencia. Y sostiene que la relacionalidad múltiple, cuando es potenciada por lo útil, constituye la base ontológica de la reciprocidad positiva, esto es, del hombre como lo más útil para el hombre. Examina la mutua dependencia entre los súbditos y el complejo de imperium y multitudo como causa de la concordia y de la discordia, pues ella teje la posibilidad o la imposibilidad de una utilidad común. Y destaca el modo en que Spinoza pasa de la relación entre individuo racional y civitas a la noción de multitud como potencia que define la diferencia de lo político, aunque no sin relación con lo ético; y a la multitud libre como figura política de la utilidad común que instituye el mejor imperium.

Palabras clave: Spinoza, reciprocidad, utilidad común, multitud libre.

\section{Abstract}

The paper analyses the relationship between power, utility and right in Spinoza's political philosophy. It explains utility from the relational character of existence. And it maintains that, when empowered by what is useful, multiple relationality is the ontological basis of positive reciprocity, that is, of man as the most useful thing for man. It examines the mutual dependence between the subjects and the complex arrangement of imperium and multitu$d o$ as the cause of both concord and discord since it weaves as much the possibility as the

Recibido: 25/03/2020. Aceptado: 30/06/2020. 
impossibility of a common utility. And it highlights the way Spinoza passes from the relationship between a rational person and civitas to the notion of the multitude qua power that defines the political as a differentiated realm, although not unrelated to the ethical; and to a free multitude as the political figure of common utility that establishes the best imperium.

Keywords: Spinoza, reciprocity, common utility, free multitude.

En la Parte IV de la Ética ${ }^{1}$, ya desde el Prefacio, Spinoza identifica el aumento de la potencia de una persona con su pasar a una mayor perfección, con su alegría, su utilidad y sus juicios de aprobación. A mayor potencia, más perfección, más alegría, mayor utilidad en nuestras acciones y un juicio más acertado sobre lo que nos conviene. La disminución de la potencia conlleva todo lo contrario: imperfección, tristeza, inutilidad y desacierto. La potencia es susceptible de aumentar o disminuir, de hecho, en los seres finitos se define por esa variabilidad.

Cuando en su filosofía política Spinoza equipara el derecho a la potencia, convierte a aquel en una facultad variable ligada, igualmente, a la mayor o menor perfección, a la utilidad o la nocividad, la alegría y la tristeza y lo bueno y lo malo. De la misma manera que todo lo que existe, por el hecho de existir, posee un cierto grado de potencia, por esa misma razón disfruta de una cierta proporción de derecho. En la medida en que su afán de vida, su capacidad de obrar, su perfección, crezcan, así se incrementará su derecho.

$\mathrm{Al}$ introducir en el Tratado político ${ }^{2}$ la idea de una potencia de la multitud o de la civitas $^{3}$ (TP 5/1), Spinoza traslada al nivel político todas las consideraciones de la potencia que había analizado a nivel ético. Así, la

${ }^{1}$ Citaré las referencias a la Ética (E) de Spinoza comenzando siempre por el número de la parte correspondiente. Luego, Pr: Praefatio; Ap: Appendix; P: Propositio, seguida del número de la proposición; también van seguidas de su número C: Corollarium, S: Scholium, Ax: Axioma, D: Definitio, L: Lema, Pos: Postulatum y C: Caput. D después de P y número: Demonstratio; E: Explicatio. Cuando lo considere útil, añadiré detrás de dos puntos la página de la edición de Gebhardt sin referencia al volumen, que en este caso es el segundo.

${ }^{2}$ Las referencias al Tratado político (TP) las citaré por el número del capítulo y, separado por barra inclinada, el número del artículo.

${ }^{3} \mathrm{Al}$ igual que Bernard Pautrat en su versión francesa del Tratado político de Spinoza, y por sus mismas razones, mantengo el término "imperium" sin traducir a lo largo del artículo y, aunque él sí lo hace, tampoco traduzco civitas. A imperium y a civitas les ocurre como a conatus. Son conceptos claramente explicitados por Spinoza -imperium es el derecho que se define por la potencia de la multitud (TP 2/17) y civitas, el cuerpo íntegro del imperium (TP 3/1) - que pierden nitidez al intentar buscar un término equivalente en francés o español. 
potencia no es sólo la esencia de los individuos, ni de los gobernantes como en el Tratado teológico-político (TTP 16: 195) ${ }^{4}$, sino también de la multitud y de la civitas. Una potencia común define el derecho común. E incluye una mayor perfección común, una utilidad común, una afectividad e imaginación comunes y un bien común. Y, en consecuencia, una razón común ${ }^{5}$.

De todas estas expresiones de la potencia, la determinante, la que define la conexión entre lo individual y lo común, es la utilidad.

\section{Lo verdaderamente útil}

En el artículo 1 del capítulo V del Tratado político, Spinoza afirma que la civitas es máximamente potente y de su derecho (sui juris) en la medida en que se funda en la razón y se dirige por ella. Esta es la expresión del encuentro más estrecho entre el conocimiento y la civitas. La civitas, al igual que el individuo, será más potente cuanto mejor conozca y más ame la verdadera utilidad. En este caso, la civitas adquiere una mayor potencia cuando el conocimiento de la verdadera utilidad — la razón— ha producido y produce sus instituciones y decisiones.

Para entender la vinculación entre razón y potencia social, Spinoza nos remite al artículo 7 del capítulo III del mismo Tratado político, cuyos términos reproduce el artículo 1 del capítulo V. El argumento a favor de que la civitas más potente y que en mayor grado es de su derecho sea la fundamentada y dirigida por la razón descansa en la idea de que el derecho de la civitas es determinado por la potencia de "la multitud que se conduce como una sola mente" 6 . Ya que, "el único modo en que podemos concebir esta unión de los ánimos (animorum unio) es que la civitas intenta al máximo lo que la sana razón enseña ser útil a todos los hombres"7.

${ }^{4}$ El Tratado teológico-político (TTP) lo citaré por el número del capítulo y, separada por dos puntos, la página de la edición de Gebhardt sin referencia al volumen, que en este caso es el tercero. Pr: Praefatio.

${ }^{5}$ Siguiendo la letra de las tres proposiciones de las nociones comunes, E 2P37, 38 y 39, por "común" podemos entender, en principio, lo que está igualmente en la parte y en el todo.

${ }^{6}$ Sobre la traducción de "multitudinis, quae una veluti mente ducitur" por "la multitud que se conduce como una sola mente", remito a F. J. Espinosa Antón, "Être une multitude et agir comme une seule âme”, en M. L. Ribeiro Ferreira, D. Pires Aurélio, O. Feron (eds.), Spinoza, ser e agir, Lisboa, CFUL, 2011, p. 146.

${ }^{7}$ No siempre seré enteramente fiel a las traducciones al español de las obras de Spinoza que referencio en la bibliografía. 
Y, ¿qué es lo que la razón enseña a todos los hombres como lo útil? En el TP, Spinoza ha dado ya la respuesta en los artículos 13-15 del capítulo II. Lo más útil para un hombre es convenir y juntar sus fuerzas con otros hombres: a) porque unidos pueden más sobre la naturaleza que por separado - lo que hay que entender por los artículos siguientes en el sentido de que la potencia que acumulan juntos es mayor que la suma mecánica de las potencias individuales- (TP 2/13); b) porque, de lo contrario, encontrará frente a sí a su peor enemigo (maximus hostis), las demás personas (TP 2/14); y, c) porque, en definitiva, la potencia individual en el estado de naturaleza, esto es, al margen de la unión con otros seres humanos, es en realidad ninguna (magis opinione quam re) (TP 2/15).

En la Ética, encuentra Spinoza una fórmula para responder a esa pregunta que es todavía más directa: la razón nos enseña a todos que nada es más útil al hombre que el hombre (E 4P18S) ${ }^{8}$. La unión de los ánimos de TP 3/7 es posible allí donde se entiende, y en la medida en que se entiende, que el hombre es lo más útil para el hombre. O, dicho de otra manera, donde se conoce el carácter necesariamente relacional o social de la vida humana. De ahí que, aunque con cautela, Spinoza vuelva sobre la idea aristotélica y tomista de la naturaleza social del ser humano9. Con cautela, con cierta distancia, decimos, porque Spinoza no entiende la socialidad como una mera relación entre individuos humanos, sino enteramente inmersa en la interdeterminación entre cosas singulares, humanas y no humanas: en la múltiple relacionalidad. Este es el principio ontológico que expone al comienzo del pasaje que acabamos de citar y se sigue, como veremos en detalle en el siguiente apartado, del hecho de que el cuerpo necesita de muchos cuerpos para regenerarse y de la simultaneidad entre cuerpo y mente ${ }^{10}$.

Podemos avanzar entonces desde aquí que la multitudo, cuya animorum unio genera la potencia que determina el derecho de la civitas, es esa composición conflictiva (afirmación y resistencia) entre tramas afectivas que ponen en relación individuos humanos y no humanos esforzándose por perseverar en el ser"1. Lo que podemos llamar "multitud compleja" es un objeto específico del conocimiento político. Es la expresión colectiva de la múltiple relacionalidad en la que de manera esencial está inmerso lo huma-

${ }^{8}$ Cf. también E 4P35C1 y 4P35C2.

${ }^{9} \mathrm{Cf}$. E 4P35S y TP $2 / 15$.

${ }^{10} \mathrm{Cf}$. E 2P13Pos4 y E 2P14.

${ }^{11}$ Seguimos en este punto a V. Morfino, "La multitud en la lectura de Negri o la desarticulación de ontología e historia”, en Youkali. Revista crítica de las artes y el pensamiento, 13 (2012), p. 76. 
no. Es más, la potencia de la multitud es máxima y esta es de su derecho, se autogobierna, en mayor grado cuando se conoce a sí misma y se ama, celebra su vida, como esa expresión necesaria de la múltiple relacionalidad esencial del ser humano y de la naturaleza en su totalidad ${ }^{12}$.

\section{Relacionalidad y utilidad}

Si el conocimiento ético fundamental en la filosofía de Spinoza es la verdad de que nuestra esencia es el conatus, el principio político básico es el carácter necesariamente relacional y múltiple del ser humano, su inclusión en lo común. La ignorancia concreta contenida en el mito de la voluntad libre, por la que somos conscientes de nuestros apetitos y acciones, pero ignorantes de sus causas, consiste en no conocer el conatus como causa de nuestra conducta. La ignorancia concreta propia del mito de los "hombres superiores", es decir, de toda teoría y práctica de la desigualdad social ${ }^{13}$, radica en el desconocimiento de la esencial y radical relacionalidad humana, que es, como el conatus, una característica común de los modos finitos, es decir, un principio que comparten todas las cosas singulares.

En el pasaje de E 4P18S que hemos citado, Spinoza remite a la física de los cuerpos de la Parte II, en especial al postulado 4 extraído de ella. Este postulado dice que "el cuerpo humano necesita, para conservarse, de muchísimos otros cuerpos, y es como si estos lo regenerasen continuamente". La física de los individuos compuestos desarrolla, a su vez, el principio de interdeterminación que Spinoza había expuesto en E 1P28. La proposición 14 de esta Parte II —esto es, la primera proposición tras los postulados de la física de los cuerpos- se encarga de extraer las consecuencias que de ellos se derivan para la mente: "La mente humana es apta para percibir muchísimas cosas, y tanto más apta cuanto de más maneras pueda estar dispuesto su cuerpo".

${ }^{12}$ Cf. F. del Lucchese, Conflict, Power, and Multitude in Machiavelli and Spinoza. Tumult and Indignation, Londres, Continuum, 2009, p. 149.

${ }^{13}$ Que Dios no es un rey y que los reyes u otros gobernantes no son como dioses es una constante de la filosofía de Spinoza que une la crítica al finalismo en la ontología y la crítica a la monarquía absoluta en política. Cf. TTP 4: 62, TTP 5:74, TTP 17: 204 y TP 7/1. Cf. F. J. Espinosa Antón, "La igualdad de los hombres en Spinoza”, en M. L. de la Cámara y J. Carvajal (eds.), Spinoza y la antropología en la modernidad, Hildesheim, Olms, 2017, pp. 309-318. 
La disposición para ser afectado y la aptitud para afectar van juntas siempre que Spinoza aborda la conexión entre el cuerpo humano y los otros cuerpos y siempre son cualificadas por Spinoza como múltiples (plurimi modi). Y ambas hay que entenderlas en tanto que despliegues de una capacidad, una efectividad, ya que Spinoza piensa que tanto la pasividad como la actividad son formas de la causalidad: en el primer caso hablamos de una causa parcial, en el segundo, de una adecuada (E 3D2). En esta proposición, la efectividad de la mente simultánea a la del cuerpo, su aptitud, es la percepción, que no deberá pensarse, por tanto, únicamente como efecto, sino al mismo tiempo como causa, incluso si es parcial. Ahora bien, la disposición del cuerpo y la aptitud simultánea de la mente se explican por su múltiple relacionalidad esencial, porque son modos inmersos en una red compleja de interdeterminaciones. La disposición, la aptitud del cuerpo y la mente y, en definitiva, la relacionalidad múltiple, desempeñan un papel fundamental también precisamente para la definición del concepto de utilidad en E 4P38.

Aquello que dispone al cuerpo humano de suerte que pueda ser afectado de más modos, o aquello que le hace apto para afectar de más modos a los cuerpos exteriores, es útil al hombre, y tanto más útil cuanto más apto hace al cuerpo para ser afectado, o para afectar a otros cuerpos, de más maneras; y, por contra, es nocivo lo que hace al cuerpo menos apto para ello ${ }^{14}$.

Es imposible, por tanto, saber qué es lo que nos conviene verdaderamente si no partimos del conocimiento de nuestra inevitable conexión diversa con los cuerpos que nos rodean, de la necesidad de que nos afecten y de que les afectemos de muchas maneras. Pero, es más, y esto es lo fundamental, la utilidad no sólo parte de la relacionalidad múltiple, sino que esta es también su medida. Lo más útil es lo que potencia y amplifica nuestra relacionalidad, nuestro ser afectados y afectar. No hay utilidad, por tanto, fuera de ella, no hay vida, no hay perfeccionamiento, ni libertad al margen de la relacionalidad. Nuestro conatus, nuestro deseo es relacionalidad múltiple condensada. Y nuestra relacionalidad múltiple, es conatus expandido. Sólo así se entiende la doble perspectiva que Spinoza proyecta sobre el ser humano.

La capacidad de afectar y ser afectado de muchas maneras se asienta, como no puede ser de otro modo, en la forma del cuerpo (E 4P39D). La potencia como capacidad de afectar y ser afectado de muchas maneras es una relación de relaciones. Existe, como explica Balibar ${ }^{15}$, en un doble nivel

\footnotetext{
${ }^{14}$ E 4P38, M. Cf. también E 4P38D, E 2P39C y E 5P39 y su escolio.

${ }^{15} \mathrm{Cf}$. É. Balibar, "Individualité et transindividualité chez Spinoza", en Spinoza politique. Le transindividuel, op. cit., pp. 211 y ss.
} 
de complejidad: la forma del cuerpo y sus relaciones con el entorno. Es conatus / commercium. Requiere, por tanto, para ser conocida de una doble mirada combinada que atienda a ambos niveles de complejidad. Precisa de la ética y de la política en su relación diferencial.

\section{El mutuo perfeccionamiento}

La construcción teórica de Spinoza discurre desde la interdeterminación de todos los modos finitos de E1P28 a la disposición y la aptitud de mente y cuerpo para afectar y ser afectados de muchas maneras de E $2 \mathrm{P} 14$ y de la múltiple relacionalidad humana de esta, al índice para determinar la utilidad y la nocividad y, con ellas, lo bueno y lo malo (E 4D1 y 2) de E 4P38. Esta vinculación entre relacionalidad múltiple y utilidad hay que tenerla muy presente a la hora de entender la segunda parte de E 4P18S. Ya que, ¿qué significa, desde esta perspectiva, que nada es más útil al hombre que el hombre? Quiere decir que aquello que hace que el cuerpo y la mente de un hombre sean más aptos para afectar y ser afectados de muchos modos es la ayuda proporcionada por otros hombres. Lo que es más, o verdaderamente, útil es el mutuo empowerment, la mutua potenciación que conduce a establecer relaciones productivas con otros muchos cuerpos y otras muchas mentes. Como dice Hasana Sharp:

Los fenómenos, los encuentros, las experiencias y los seres útiles son aquellos que “disponen” al cuerpo haciéndolo más receptivo y, por tanto, más activo. La utilidad nombra un tipo de implicación corporal que provoca que los seres afectados se abran cada vez más al mundo y, por eso mismo, sean cada vez más capaces de afectar a $\operatorname{otros}^{16}$.

Solo que, entre esas utilidades, son los otros seres humanos quienes en mayor medida tienen que acoger el cuerpo y la mente de un ser humano para hacerlos más aptos. Y el énfasis hay que ponerlo en la reciprocidad, en la ayuda mutua entre humanos. La mutua utilidad es la utilidad común, que según E 4P18S, deben buscar todos juntos para sí. Esta será entonces lo verdaderamente útil ${ }^{17}$, la utilidad común que sea utilidad individual y la utilidad individual que sea utilidad común ${ }^{18}$. La utilidad es común porque afecta de manera recíproca a la parte y al todo, a los súbditos y a la civitas.

${ }^{16}$ H. Sharp, Spinoza and the Politics of Renaturalization, Chicago, University of Chicago Press, 2011, p. 102.

${ }^{17}$ TTP 5: 73 y TTP 16: 191.

${ }^{18}$ Cf. Cicerón, De officiis, III, 52. 
En este aspecto, por tanto, cabe discrepar de Sharp cuando señala que "la utilidad spinoziana no es la noción "utilitarista" con la que se la suele confundir. La noción de utilidad no implica que las otras personas son los instrumentos más efectivos para satisfacer nuestras preferencias"19. Nosotros sí consideraremos que la mutua utilidad humana de Spinoza tiene algo en común con el utilitarismo de Jeremy Bentham y James Mill. Sí creemos que Spinoza estaría de acuerdo con ambos en este punto $^{20}$. La diferencia estaría más bien en que el utilitarismo plantea como solución al conflicto por la apropiación de los efectos de la potencia del otro el criterio formal de la mayor felicidad del mayor número medida por el dinero, lo que a su vez obliga a pensar a los individuos como seres aislados o aislables. Para Spino$\mathrm{za}$, por el contrario, la resistencia a la dominación se fundamenta en la reciprocidad positiva, en la capacidad para generar relaciones más potentes. La resistencia es la potencia resultante de la combinación de las potencias individuales revertida sobre el incremento de la aptitud para ser afectado y afectar de muchas maneras de cada cuerpo-mente. Y esto nos lleva a pensar siempre el individuo en relación múltiple, de ahí, las medidas concretas de Spinoza: libertad de expresión, grandes asambleas, ejército popular... En Bentham y Mill, la utilidad humana espontánea sólo se plantea como problemática porque ya se tiene de antemano la respuesta en forma de un criterio externo: la cuantificación de la utilidad. En Spinoza, el análisis del problema abre paso a la solución. Es porque las personas son lo más útil para las personas por lo que se genera el conflicto y, también, por lo que se trama la concordia ${ }^{21}$.

Recordemos que, tanto en el TTP como en el TP, Spinoza define la servidumbre o el dominio precisamente como una utilidad no recíproca. "Siervo es quien está obligado a obedecer las órdenes del señor que solo buscan la utilidad del que manda" define en TTP 16: 195. Igualmente, en TP 5/6, la multitud sometida "es, por la fuerza, del vencedor (esse victoris cogitur)" y la finalidad del imperium sostenido sobre el derecho de guerra es hacer siervos. En esta misma línea, la relación de alterius juris expuesta en TP 2/9-11 puede entenderse como una alienación de la potencia en la medida en que

${ }^{19}$ H. Sharp, Spinoza and the Politics of Renaturalization, op. cit., p. 102.

${ }^{20}$ Cf. C. B. Macpherson, The Life and Times of Liberal Democracy, Oxford, Oxford University Press, 1979, p. 26, a quien seguimos en nuestra lectura de Bentham y Mill.

${ }^{21}$ El republicanismo de Spinoza, opuesto al individualismo de Bentham y Mill, se sostiene no sobre el télos de la comunidad, como en la tradición aristotélica, sino sobre la democratización de las múltiples relaciones en las que ya siempre estamos inmersos. En Spinoza no hay regímenes "desviados". 
otro se apropia de sus efectos, es decir, lo alienado y lo apropiado sin reciprocidad son los efectos producidos por las acciones del sojuzgado, que no pierde su potencia sino el control sobre sus efectos y, por tanto, la posibilidad de que reviertan en su aumento, de que sean útiles para él o ella: pierde su utilidad. La dominación separa la potencia de su perfeccionamiento, la mantiene en un ciclo de servidumbre en lugar de favorecer que se adentre en un ciclo de liberación.

A nivel político, el ciclo de liberación —el aumento de nuestra potencia sostenido sobre el conocimiento de su verdadera naturaleza afirmativa y relacional- es proceso de democratización; y su estrategia de aumento de potencia es la apropiación común de la potencia común de la multitud.

El ciclo de servidumbre, aquel que reproduce la ignorancia, es, entonces, a nivel político, dominación. La dominación política no es la única relación de poder asimétrica, pero en ella, tal como concibe Spinoza el imperium según las formas políticas del siglo XVII europeo, esta explicación se cumple de un modo totalizante. En efecto, la potencia común de la multitud es el efecto de la combinación de las potencias individuales que los gobernantes dominadores se apropian, o "confiscan" como dice Matheron ${ }^{22}$, y que define su derecho. Apropiarse la potencia común significa conducirla no hacia el perfeccionamiento de todos los individuos, sino al sostenimiento de la desigualdad de poder entre dominantes y dominados, en la creación no de ciudadanos virtuosos, sino de siervos. Se abre en este punto uno de los conflictos determinantes de la vida política: la pugna entre la apropiación común y la apropiación privada de la potencia común. La apropiación común es la apropiación del efecto de la combinación de las potencias de todos realizada por la multitud y tiene su forma política en la democracia o en la democratización ${ }^{23}$. La apropiación privada es el imperium dominación en el régimen que sea: la monarquía absolutista, la aristocracia oligárquica o la democracia excluyente.

${ }^{22}$ A. Matheron, "Spinoza et le pouvoir", en Études sur Spinoza et les philosophies de l'âge classique, Lyon, ENS Éditions, 2011, p. 74.

${ }^{23}$ Sigo aquí a A. Matheron, "Le 'droit du plus fort' : Hobbes contre Spinoza”, p. 153, y "La fonction théorique de la démocratie chez Spinoza et Hobbes", p. 165, en Études sur Spinoza et les philosophies de l'âge classique, op.cit. 


\section{El efecto cruzado de la dominación}

De esta concepción de la libertad y la servidumbre desde el punto de vista de la relacionalidad múltiple parte la idea de Spinoza de que este perfeccionamiento de la potencia que se trunca en la dominación se pierde para todos, tanto para el siervo como para el dominante. Para el primero es obvio. Pero, si el segundo lo malogra también, es porque, de darse el caso contrario, el perfeccionamiento de la potencia redundaría en una potencia común que sería útil, más útil, también para el dominante. Este es un argumento que recorre la entera obra política de Spinoza. Es el argumento por el que en el capítulo XX del TTP conviene a las "summae potestates" conceder la libertad de juzgar (TTP 20: 245). Y por el que, en TP 6/8, establecer firmemente los fundamentos del imperium monárquico implica garantizar, al mismo tiempo, la seguridad del monarca y la paz de la multitud: el rey "es más de su derecho cuanto más vela por la salvación de la multitud". El motivo de la indignación popular en TP 3/9 y TP 4/4 y TP 4/6 es precisamente que el dominante no atiende a este consejo. Y el principio general de que en política no se trata de confiar en las promesas de nadie, expuesto en TP 1/6 y TP 6/3, apunta a la necesidad de institucionalizar este conocimiento.

En la lógica de Spinoza, lo importante no consiste, sin embargo, en apelar al dominante para que, por su propio bien, procure por la salvación del dominado. Implica, más bien, entender que el hecho de que la pérdida sea mutua redobla el conflicto, convirtiéndolo en una contradicción interna en cada uno de los extremos. En el dominante, se enfrentan el esfuerzo por reproducir la dominación y el cuidado de evitar la pérdida del perfeccionamiento. En TP 8/5, por ejemplo, el modo en que la asamblea aristocrática puede superar su miedo a la multitud consiste en integrar el derecho de esta en la constitución del imperium, convirtiendo ese derecho en potencia estatal, de suerte que mantenga el poder supremo en manos de la asamblea y acabe con el poder de la multitud separada (TP 8/5 $)^{24}$.

En los dominados, la lucha por liberarse del poder impuesto del dominante es temperada por la precaución de no crear una nueva dominación o la ruina de la sociedad. Ejemplos de esta prudencia son las lecciones que Spinoza extrae de Maquiavelo en TP 5/7: el hecho de que de nada sirve acabar con el tirano si no se acaba con las causas de la tiranía y que la multitud libre no debe confiar su salvación a un solo hombre ${ }^{25}$; así como la multitud libre como condición afectiva de una monarquía libre en TP 7/26.

${ }^{24}$ Cf. también TTP 16: 194.

${ }^{25}$ Cf. L. Bove, "Introduction : De la prudence des corps. Du physique au politique”, en Spinoza, Traité politique (traduction d’É. Saisset révisée par L. Bove), París, LGF, 2002, p. 43. 
Maquiavelo parece, en efecto, la fuente de inspiración de toda esta temática. Clave es, por ejemplo, su afirmación de que "el príncipe debe tener poco en cuenta las conjuras cuando tenga el favor del pueblo, pero si el pueblo es su enemigo y le odia, debe temer de cualquier cosa y a todos" 26 . El favor del pueblo es aquí el garante del poder del príncipe, lo que supone dotar al pueblo de un poder propio, de una potencia, que si se sitúa en contra del príncipe conlleva la ruina de este. El príncipe está así supeditado al pueblo, ya que sin él nada puede. Maquiavelo invierte la relación de poder político tradicional. No es el pueblo el que debe obedecer al príncipe, sino el príncipe al pueblo, si quiere mantener su poder. En esta inversión se concentra la problemática que Spinoza va a traducir como dependencia del derecho del imperium de la potencia de la multitud, y va a conducir hasta la determinación de la libertad de la multitud de TP 7/31. La libertad de la multitud reside en su capacidad para hacer efectivo el poder que, de cualquier manera, posee frente a los gobernantes.

El miedo de los gobernantes y el miedo de las masas, por el que unos y otras son temibles si no temen, se retuercen sobre sí mismos y se pueden convertir en prudencia ${ }^{27}$. Se generaría así un efecto cruzado sobre la base del cual Spinoza va a diseñar los sistemas de relaciones de poder y contrapoder ${ }^{28}$ de modo que nada de lo que concierne a la liberación común se haga descansar completamente en el compromiso (fides) de nadie (TP 6/3). Pero, principalmente, sobre esa base se construye la posibilidad de una comunidad de perfeccionamiento. De ahí es de donde puede surgir una sociedad dedicada a cultivar la vida racional y no simplemente a evitar el miedo (TP $5 / 5$ y $5 / 6$ ).

\section{La mutua dependencia entre los súbditos y el complejo imperium-multitudo}

Antes de continuar, conviene insistir en que lo dicho hasta ahora significa que los ánimos de la multitud que actúa como una sola mente se unen en la medida en que entienden que ya siempre están unidos o que ya siempre están en relación múltiple esencial. Esa unión aumenta su potencia cuando

${ }^{26}$ N. Maquiavelo, El príncipe (edición bilingüe), Madrid, Tecnos, 2011, cap. XIX, p. 184.

${ }^{27}$ Cf. É. Balibar, "Spinoza, l'anti-Orwell. La crainte des masses", en La crainte des masses : politique et philosophie avant et après Marx, París, Galilée, 1997, p. 78. y É. Balibar, "Spinoza et la politique”, en Spinoza politique. Le transindividuel, op. cit., p. 89.

${ }^{28}$ Cf. A. Negri, La anomalía salvaje. Ensayo sobre poder y potencia en B. Spinoza, Barcelona, Anthropos, 1993, p. 340. 
fortalece la concordia — que coincide con la verdadera, mutua o común utilidad en el Tratado político. Y es de su derecho si, colectiva, no sólo individualmente, los ciudadanos no se dejan engañar, ya que es a través del engaño como la facultad de juzgar se subordina al derecho de otro (TP 2/11). Más que nada, esta retención del derecho resulta expresamente de neutralizar el mito de los hombres "sobrehumanos", vertiente ideológica de la dominación, de la alienación política.

La esencial relacionalidad múltiple, la utilidad común y el efecto cruzado de la dominación explican también los artículos 2 y 3 del capítulo V del TP y su consecuencia lógica: la no-dominación tal como es descrita por los artículos 4, 5 y 6 . Así es como lo resume la sentencia del artículo 2: Homines enim civiles non nascuntur, sed fiunt. Los hombres, que, aisladamente o en el estado de naturaleza, no tienen una potencia real, como dice Spinoza en TP 2/15, tienen que socializarse para adquirirla. Depende, por tanto, del modo en que estén organizados el imperium y la civitas para que esa socialización dé como resultado una ciudadanía impotente, incapaz de vivir en concordia, lo que a su vez redundará en una mayor precariedad del imperium (TP 5/2). O, al revés, unos súbditos más potentes, lo que redundará en una civitas más potente (TP 5/3).

La esencial relacionalidad múltiple de los seres humanos implica racionalmente, por tanto, una utilidad común, una concordia que supone la mutua dependencia entre la potencia de los súbditos y la de la civitas o el imperium $^{29}$. Es el conocimiento de la utilidad común y la mutua dependencia, en la medida en que se impone sobre las ideas contrarias, lo que produce una prudente institución de los derechos y un cuidado de la concordia, es decir, de eso mismo que se conoce, pues la concordia no es algo distinto de la utilidad común y la mutua dependencia entre las potencias de los súbditos y la civitas.

Así, sería contradictorio pensar que este conocimiento de las relaciones de reciprocidad, de concordia entre los ciudadanos y de mutua dependencia entre los súbditos y la civitas, pudiera ser monopolizado por uno o por unos pocos. Eso exigiría pensar a estos pocos como individuos separados del resto, por encima del resto, como los hombres sobrehumanos de los que hemos hablado, como hombres sustraídos a la reciprocidad. Serían hombres deshonestos (turpes), al poner trabas a la amistad con otros hombres (E 4P37S1), y no extraerían la conclusión que expresa la proposición E

${ }^{29}$ Cf. É. Balibar, "Spinoza et la politique”, en Spinoza politique. Le transindividuel, op. cit., p. 127. 
4P37: "El bien que apetece para sí todo el que sigue la virtud, lo deseará también para los demás hombres, y tanto más cuanto mayor conocimiento tenga de Dios”.

Nos encontramos así frente a la contradicción más importante del Tratado teológico-político, aquella que explica el cambio que sufre la noción de multitud de esa obra al Tratado político. Digamos que el conocimiento de la utilidad común exige abolir la división entre sabios e ignorantes, entre filósofos y vulgo, no reproducirla. Ahora bien, es claro que el conocimiento de la reciprocidad como utilidad común también conlleva lo inadecuado de toda relación de alienación de derechos entre adultos y, no obstante, Spinoza sigue manteniendo en el TP esa posibilidad para el caso de los siervos y las mujeres (TP 11/3-4). La utilidad común no sólo se contradice con la postulación de humanos sobrehumanos, también con la de humanos infrahumanos. Digamos que el trabajo teórico de Spinoza no escapa a la proposición E 4P1: "Nada de lo que tiene de positivo una idea falsa es suprimido por la presencia de lo verdadero, en cuanto verdadero". Lo cual tampoco le impide a Spinoza exponer la verdad, como lo hace en las importantes precisiones de los conceptos de paz y de vida humana en los artículos 4 y 5 del capítulo V.

El conocimiento de la común utilidad y de la dependencia mutua entre súbditos y civitas debe ser un conocimiento común para ser efectivo: un saber común. El ánimo fuerte que obedece por sí mismo los decretos comunes y la vida racional que es condición de la vida en concordia son los ánimos y las vidas singulares donde ese saber común concreto, esas nociones comunes, producen sus efectos.

Aquí ya se anuncia la multitud libre. La potencia del conocimiento y del amor de la utilidad común y la mutua dependencia puede ser mayor o menor. Pensarla como mayor, como absoluta, pensarla como razón común es ya una acción que busca ampliarse, desarrollarse y extenderse.

La común utilidad supone la mutua dependencia entre súbditos e imperium porque la utilidad es común en el doble sentido de, por un lado, recíproca entre unos y otros de los ciudadanos y de, por otro, utilidad producida por todos, formada por la concurrencia de los esfuerzos de todos. En esa doble vertiente, el imperium y el súbdito son los puntos cambiantes de partida y de llegada de la concurrencia y la reciprocidad. Spinoza no deja de preguntarse hasta dónde llega la mutua dependencia de súbditos e imperium, hasta donde llega esta máxima interpenetración de ética y política. Por eso, le resulta imprescindible referirse en TP 5/6 a la multitud libre, como multitud constituyente y como multitud compleja cuyas condiciones 
de vida le permiten crear el mejor imperium. La relación específicamente política es la que se establece entre imperium y multitud, porque la multitud es el espacio de la común utilidad y del conocimiento común. Pero esta relación específica tiene que integrar una relación mixta, ético-política, del compuesto imperium-multitud con los ciudadanos considerados individualmente. La relación ético-política es fuente de liberación o de aislamiento para los súbditos, tomados uno a uno. Y termina dando la medida de la virtud y el derecho de la civitas.

El imperium productor de concordia es, entonces, el imperium de la no dominación de una parte de la sociedad sobre otra. No es sólo el lugar de la paz, de la ausencia de sediciones o de respeto a las leyes, sino el espacio donde los hombres llevan, individual y colectivamente, una vida racional. La oposición no es entre orden y desorden en Spinoza, sino entre libertad y dominación. La cuestión es qué tipo de apropiación sufre la potencia común. Si es una apropiación privada, que exige que haya una parte de la sociedad rebelde al imperium o inerte en su sometimiento al mismo. $\mathrm{O}$ es una apropiación común por la que la potencia de cada ciudadano se perfecciona al tiempo que se perfecciona la potencia común. La potencia común requiere una apropiación, una organización institucional de la civitas que, o bien, posibilite la "confiscación" privada o bien realice una apropiación común. Esta última es la virtud y el derecho absoluto de la civitas: que la potencia común sea apropiada por el común y no "confiscada" por una parte. Seguridad y libertad son, desde esta perspectiva, exactamente lo mismo. La inseguridad y el desorden, la inercia y la animalidad son obra de la dominación.

\section{Civis non sui sed civitatis juris est}

Los límites de la dependencia mutua entre súbditos e imperium los había establecido Spinoza en el capítulo III, artículos 5-10. En el artículo 5, plantea el problema de la manera más cruda posible: "el ciudadano no es de su derecho, sino del de la civitas". El argumento descansa en la idea de que el cuerpo (íntegro) del imperium, la civitas, tiene que conducirse como una sola mente y que eso supone que la voluntad de la civitas equivale a la voluntad de todos y cada uno (TP 3/5). Entiéndase que Spinoza está planteando esta equivalencia no como algo que debería ser, sino como algo que ocurre de hecho. De facto, desde el punto de vista del individuo, sin más consideración, las leyes operan como si las hubiera aprobado él mismo. La 
imaginación de una voluntad unánime es "objetiva”. De la misma manera que no podemos dejar de recibir la impresión de que el sol se encuentra a doscientos pies, aunque conozcamos la verdadera distancia a la que se aleja de nosotros (E 2P35S), no podemos dejar de sentir la voluntad de la civitas como si fuera la nuestra. La razón es que la relación de fuerzas entre individuo e imperium es tan asimétrica que la potencia del primero se reduce a la que la civitas le otorga derecho para extraer de ella misma (TP 2/16). Su potencia es una potencia social expresada individualmente. Su conducta activa será, por tanto, una expresión de las leyes estatales. Fuera de ellas, sólo le queda la soledad, el miedo y la miseria. Incluso si esos decretos sociales son injustos, la asimetría de poder no le deja otra opción prudente que obedecer.

Spinoza piensa en el límite, sin componendas. Ello le sirve para exponer todas las condiciones de la relación individuo-civitas. La pregunta se sigue de inmediato, pero, si esto es todo lo que cabe decir de la conexión entre el individuo y la civitas, ¿no es la vida común en su conjunto completamente irracional en tanto que obliga a cometer injusticias sin ofrecer alternativa? ${ }^{30}$ La respuesta de Spinoza se despliega en tres tiempos. Contesta en el artículo 6 desde el punto de vista de la ética o del individuo que desea regirse por la razón. Los artículos 7, 8 y 9 responden desde la perspectiva de la política, a saber, de la potencia / derecho de la civitas en relación con la potencia de la multitud. Y el artículo 10 da una solución al problema teológico-político.

Desde la óptica ética del individuo que desea ser racional, Spinoza ofrece, en el artículo 6, cuatro consideraciones. La primera es definitoria de la concepción spinozista de la política: mientras las pasiones manden sobre los hombres en general, ninguno de ellos, ni siquiera el sabio, puede ser plenamente de su derecho. El conflicto es irreductible para todos y el sabio o el hombre racional no pueden vivir al margen de los demás hombres y, por tanto, al margen del conflicto. La relacionalidad múltiple es tan esencial para él como para cualquier otra persona o, incluso, para cualquier otro ser de la naturaleza. No hay vida humana fuera del conflicto y de su institucionalización. Este es un conocimiento racional, una noción común.

Es más, y ahora viene la segunda consideración, si lo racional, entendido como lo verdaderamente útil para nuestra conservación, es la paz, desear la paz conlleva respetar los derechos comunes que la hacen posible. Cuanto

${ }^{30} \mathrm{O}$, con otras palabras, ¿no convierte la sociedad, cualquier sociedad, a los hombres de seres racionales en bestias o autómatas, como dice en TTP 20: 241, o los reduce a la inercia, la bestialidad, la barbarie o la soledad, como apunta en TP $5 / 4$ y TP 6/4? 
más racional y libre sea la conducta de un individuo, con más convicción cumplirá las leyes.

En tercer lugar, si lo racional para un individuo en el estado de naturaleza es librarse del miedo y de la miseria, pero eso es imposible hacerlo por sí solo, entonces más racional será ayudar a que esa liberación se consiga desde el colectivo político (TP 3/6). Obedecer la ley supone desplazar al nivel civil o colectivo lo que es imposible resolver a un nivel meramente individual o natural.

Por último, si se da el caso de elegir entre sacrificar la razón de una forma y sacrificar la razón de la otra, entre la razón de la desobediencia de una ley injusta y la razón de la utilidad que aporta el estado civil, lo racional es elegir el mal menor: la obediencia.

En definitiva, Spinoza contesta desde el marco establecido en EIV. Como en esa parte de la Ética, lo racional, lo verdaderamente útil, allí donde nuestra potencia, nuestra libertad, tienen alguna opción es la civitas. Y fuera de ella no hay posibilidad alguna de virtud (E 4P73).

Es importante, sin duda, que Spinoza avance hasta ahí y dé una respuesta ética al problema, pero es fundamental que no se detenga en ella y busque dar una respuesta específicamente política, claramente diferenciada de la anterior. Es lo que hace en los tres artículos siguientes.

En el artículo 7 encontramos un texto que, como hemos visto, es la base de todo el capítulo V, pero que leído dentro de la cadena argumental en la que surge, adquiere un nuevo sentido. Es cierto, dice Spinoza, que el ciudadano no es autónomo respecto a la civitas, ya que la potencia de esta es inconmensurable comparada con la suya, pero también es verdad que si una civitas quiere ser potente y mantenerse en su derecho tiene que perseguir lo que es verdaderamente útil a todos. Es decir, debe suponer una expresión individual de la potencia social en la que la conducta racional de los individuos se incremente al tiempo que el derecho de la civitas. La mutua dependencia debe funcionar con una retroalimentación positiva entre ciudadanos y civitas en la que ambos extremos de la relación vean incrementada su potencia al máximo. Y esa retroalimentación sólo puede hacerse a través de la utilidad común, recíproca y de todos, es decir, a través de la potencia de la multitud generada por la unión de los ánimos y devuelta a esos mismos ánimos para su perfección.

Esto es, por mucho que la potencia común y la potencia individual sean inconmensurables, es igualmente cierto que son mutuamente dependientes. La conversión del individuo de racional en bestia o autómata (TTP 20: 241), su reducción a la inercia, la animalidad, la servidumbre, la barbarie o 
la soledad (TP 5/4 y TP 6/4), el imperium como dominación, en definitiva, descompone igualmente a la civitas, reduce su potencia y su derecho, frena su conatus. Una sociedad de siervos bordea no merecer siquiera el nombre de civitas.

Ahora bien, ¿cómo funcionan la mutua dependencia y la utilidad común o, al menos, como podrían funcionar? A ello responden los tres siguientes parágrafos. El artículo 8 señala que la civitas sujeta al individuo sólo a través de amenazas y promesas. En estos premios o castigos se juega, se entiende, su vida, pero no encierran su entero campo de acción. Queda el pensamiento racional que ha podido desarrollarse gracias a la propia civitas. Quedan los sentimientos de amor y odio. Queda el esfuerzo por perseverar en el ser. Son los límites que se encuentra la inconmensurabilidad de la potencia común. La dominación política puede destruir al individuo, pero no lo hará sin resistencia.

En el artículo 9 encontramos la actividad política hacia la que pueden derivarse esas potencias que escapan a la sujeción: ponerse de acuerdo para provocar temor a los que, ejerciendo el poder, están fomentando las causas de la indignación de muchas personas. En la medida en que una civitas se conduce de modo que provoca daños a los ciudadanos - perjuicios que, a su vez, generan odios-, se debilita. Promueve las revueltas y de las revueltas extrae un mayor temor y una mayor debilidad. La mutua dependencia y la utilidad común tienen aquí su reverso negativo.

Entre la reciprocidad positiva y la negativa entre individuos y entre súbditos y civitas se determina la virtud y el derecho de todos ellos. Pero, en el artículo 9 queda claro que la solución al problema de la relación entre individuo y civitas es política, pasa por la utilidad común, porque ya no es decisiva la potencia aislada de un individuo, sino su capacidad para respirar y aspirar con otros (in unum conspirare) ${ }^{31}$, para generar una acción colectiva que incline el equilibrio de fuerzas hacia la racionalidad, de modo que la civitas tome las medidas oportunas que le lleven a no temer la indignación de los ciudadanos. El individuo aislado es impotente frente a la civitas, pero las acciones colectivas modulan la potencia de la multitud y determinan así el derecho del imperium y de la civitas. La multitud, su potencia, no es entonces una figura intermedia entre el individuo y el imperium ${ }^{32}$, sino la

${ }^{31}$ En ese sentido lo utiliza Spinoza en TTP 16: 191.

${ }^{32}$ Cf. F. Zourabichvili, "L'énigme de la 'multitude libre'”, en Ch. Jaquet, P. Sévérac et A. Suhamy (dir.), La multitude libre. Nouvelles lectures du Traité politique, París, Éditions Amsterdam, 2008, p. 71. 
figura propiamente política, la figura de la acción colectiva, de la utilidad común. Ya no se trata de la expresión individual de la potencia social, sino de las intensidades parciales, aunque colectivas, de esa potencia: "Y como el derecho de la civitas se define por la potencia común de la multitud, está claro que la potencia y el derecho de la civitas disminuye en cuanto ella misma da motivos para que muchos conspiren” (TP 3/9).

El concepto de multitud, en su aspecto rebelde, busca constatar las grietas que, inevitablemente, atraviesan lo social, grietas que no se articulan en lo individual sino en lo colectivo o en lo transindividual, pero en un colectivo o transindividual que es, irreductiblemente, plural o, mejor, complejo, múltiple, constituido por una correlación de fuerzas diversas de diferente intensidad. La multitud es así la expresión política de la relacionalidad múltiple, que, en su deducción racional, nos conduce a la utilidad común o concordia, a la apropiación común de la potencia común, pero que no puede abstraerse del conflicto generado por la imposibilidad humana de superar a nivel colectivo el sometimiento a las pasiones.

La rebeldía resistente a la dominación, virtud totalmente imprescindible para que el individuo no se convierta en un autómata, solo puede tener efectos reales si es compartida. La multitud libre no puede existir sin su cara rebelde, hostil a la servidumbre. La conspiración, la acción junto a otros, es lo único que puede librar al individuo de ser aplastado por una potencia común cautiva vuelta contra su persona. Aunque ello no impide que pueda confiar en la ética, sin olvidar que Spinoza juega continuamente con la relación diferencial entre ética y política.

En este sentido, el artículo 10 pone el broche a este grupo de parágrafos, descubriendo un ángulo político de la ética en su mayor expresión. El problema teológico-político es considerado directamente desde la concepción spinoziana de la religión (E 4P37S1). Además de reproducir su posición en el TTP respecto a la necesidad de que el culto externo esté regulado políticamente, el argumento que enlaza con los parágrafos anteriores es que el verdadero conocimiento y amor de Dios y el amor al prójimo, es decir, las potencias que definen al sabio spinoziano, no se pueden someter a ningún mando: "el conocimiento y el amor verdaderos de Dios no pueden estar sometidos al mando (imperio) de nadie, ni tampoco el amor al prójimo". Esta libertad respecto a cualquier mando se traduce, a su vez, en una actividad política concreta: en el ejercicio de velar por la paz y procurar la concordia como manera de participar en la ayuda mutua.

Se apunta aquí, quizás, una vía para pensar una teoría spinozista del papel político de los filósofos o de la lucha política en la teoría, que falta en 
el TP, pero se había apuntado en el TTP con la figura del hombre honesto de carácter libre (TTP 20:245). En efecto, Spinoza liga la independencia del filósofo al derecho de la sociedad como concordia, lo que no se traduce en mero respeto a las leyes, sino en una actividad concreta, junto con otros, a favor de la concordia, es decir, como estamos viendo, a favor de una sociedad fundamentada y dirigida racionalmente en la que la mutua dependencia opere según un ciclo de reciprocidad positiva o utilidad común.

\section{Conclusión: relación de mando y utilidad común}

La política se constituye como conocimiento de la vida común desde la base de que el conflicto, en sus muchas formas, es irreductible, aunque limitable. Y, también y al mismo tiempo, a partir del principio de que la civitas se esfuerza, en mayor o menor grado, por lo verdaderamente útil. De este conocimiento de lo útil y su práctica depende el derecho propio de la civitas.

Lo verdaderamente útil para el hombre es el hombre, sobre esto no cabe duda en Spinoza. Sin embargo, la utilidad interhumana, la reciprocidad positiva, tiene que entenderse completamente ligada a la relacionalidad múltiple que el ser humano, como modo de la sustancia, comparte de manera necesaria con todos los seres de la naturaleza. La utilidad es aumento y expansión de la relacionalidad múltiple, incremento en la capacidad para afectar y ser afectado de muchas maneras. Conocer lo verdaderamente útil es para el ser humano entender que su múltiple relacionalidad, sobre todo con otros seres humanos, no sólo no es un obstáculo para la libertad, sino la materia misma que la constituye.

Los seres humanos aumentan su potencia incrementando la intensidad y la multiplicidad de sus relaciones. Y la disminuyen limitándolas, empobreciéndolas. Así, pues, el aumento de la utilidad individual es lo mismo que el incremento de la utilidad común o recíproca, porque la utilidad individual no consiste en otra cosa que en la utilidad común y la utilidad común coincide con la utilidad individual. Este es el conocimiento fundamental que hace posible, en la medida en que se impone a otras ideas contrarias, la unión de los ánimos que guía a la multitud cuya potencia determina el derecho del imperium y la civitas.

El concepto de verdadera utilidad, de consistencia entre utilidad individual y utilidad común, explica, igualmente, la dominación social. Hay dominación en la medida en que parte de la sociedad está alienada de su 
utilidad. No de su potencia, sino de lo que perfecciona su potencia, de los efectos que podrían revertir en el aumento de su potencia y no lo hacen. Claro que la dominación es, en sí misma, un obstáculo para el incremento de la utilidad común y aprisiona a dominantes y dominados en un efecto cruzado que abre la oportunidad si no siempre de abolirla, sí de limitarla. Y, en un paso más, aboca a trasmutar su deseo, a desprenderse del miedo y activar la vida racional.

Tanto en el capítulo V, artículos 2 a 6, como en el cap. III, artículos 5 a 10, encontramos uno de los aspectos de la naturaleza inmanentista de la diferencia entre un imperium que gobierna sin más con derecho y otro racionalmente deseable. En esos pasajes no sólo se demuestra que la potencia a la que equivale el derecho de la sociedad puede ser mayor o menor. En los artículos del capítulo V, Spinoza establece que esa mayor o menor potencia viene determinada por la mutua dependencia entre la potencia de los súbditos y la potencia de la civitas-multitudo. La mayor o menor potencia está determinada por un principio de circularidad productiva que se mueve desde el nivel colectivo al individual, definiendo la potencia de ambos como mutuamente condicionante y condicionada. Es sobre ese principio de circularidad sobre el que se sostiene la concordia o la dominación, la apropiación común o la "confiscación" privada de la potencia común que impone servidumbre, o sea, soledad.

Los artículos del 5 al 10 del capítulo III nos permiten, por su parte, entender que la mutua dependencia entre individuo y civitas sólo adquiere forma política cuando los individuos actúan colectivamente en y sobre una correlación de fuerzas diversas de variada intensidad que Spinoza denomina "multitud" y que alcanza su grado máximo de actividad en la utilidad común o concordia, aunque nunca escape completamente del conflicto.

La ayuda mutua, la cooperación vital, no sólo integran la división del trabajo y de la propiedad, el mantenimiento de la vida y el cultivo de la mente ${ }^{33}$, sino también la institución del mando político. La relación de mando soló puede producir concordia si esa ayuda mutua materializada como utilidad común rige sobre ella, si la relación de mando es determinada por la cooperación de la multitud, por la ayuda mutua, y la perfecciona. La relación de mando, pues, no es la "ley última" de la vida en común. A pesar de que el imperium se presenta como soberanía, como una voluntad separada, como Ley, en realidad hay una ley previa a la Ley. El imperium o bien obedece a la necesidad de producir concordia o emprende la fabrica-

${ }^{33}$ Cf. TTP 5: 73, TTP XVII: 216 y TP 2/15. 
ción de servidumbre. Sobre la relación de mando impera el derecho natural, como dice Spinoza en TP 4/6 $6^{34}$, o la naturaleza o condición común de los hombres, como señala en TP $1 / 4$ y $1 / 7$, esto es, la múltiple relacionalidad que nos constituye, ya sea como utilidad común o como afectos comunes. Tanto en ética como en política, hay una ley previa a la Ley: el conatus y la múltiple relacionalidad. El imperium existe siempre junto con el juego de la concordia y el conflicto bifronte: la dominación y la rebelión, es decir, junto con el derecho natural o la naturaleza común de los hombres que en cada coyuntura no es otra cosa que la vida misma de la multitud. Esta vida múltiple y común, convulsa o pacífica, esta potencia de la multitud define el derecho de todo imperium, que nunca es, por eso mismo, soberano, pues los gobernantes no gozan de voluntad libre, ni de nada análogo que pueda llevarnos a considerar su poder como separado.

El mejor imperium, en concreto, se ciñe a la vida de la multitud libre que lo instituye. Y se sostiene en el conocimiento de que la distinción institucional entre gobernar y ser gobernado adquiere su mayor potencia, su mayor efectividad, su derecho absoluto, si se pone al servicio de la verdadera utilidad, esto es, si su estructura institucional trabaja para hacer coincidir utilidad individual y utilidad común, para la apropiación común de la potencia común. Si no se usa con ese fin, se usa con el contrario, con el fin de la dominación, conduce a hacer a la mayoría sierva de una minoría, a la apropiación privada de la potencia común.

\section{Bibliografía}

Balibar, É., "Spinoza, l'anti-Orwell. La crainte des masses", en La crainte des masses : politique et philosophie avant et après Marx, París, Galilée, 1997.

Balibar, É., Spinoza politique. Le transindividuel, París, PUF, 2018.

Bove, L., "Introduction : De la prudence des corps. Du physique au politique”, en Spinoza, Traité politique (traduction d'É. Saisset révisée par L. Bove), París, LGF, 2002.

Cicerón, M. C., Los deberes, Madrid, Gredos, 2014.

Espinosa Antón, F. J., "Être une multitude et agir comme une seule âme", en M. L. Ribeiro Ferreira, D. Pires Aurélio, O. Feron (eds.), Spinoza, ser e agir, Lisboa, CFUL, 2011.

${ }^{34}$ Cf. también TP 4/5 y TP 4/7. El resumen de los tres artículos es que el límite del poder del imperium es la resistencia de la multitud. 
Espinosa Antón, F. J., "La igualdad de los hombres en Spinoza”, en M. L. de la Cámara y J. Carvajal (eds.), Spinoza y la antropología en la modernidad, Hildesheim, Olms, 2017.

Lucchese, F. del, Conflict, Power, and Multitude in Machiavelli and Spinoza. Tumult and Indignation, Londres, Continuum, 2009.

Macpherson, C. B., The Life and Times of Liberal Democracy, Oxford, Oxford University Press, 1979.

Maquiavelo, N., El príncipe (edición bilingüe), Madrid, Tecnos, 2011.

Matheron, A., Études sur Spinoza et les philosophies de l'âge classique, Lyon, ENS Éditions, 2011.

Morfino, V., "La multitud en la lectura de Negri o la desarticulación de ontología e historia", en Youkali. Revista crítica de las artes y el pensamiento, 13 (2012).

Negri, A., La anomalía salvaje. Ensayo sobre poder y potencia en B. Spinoza, Barcelona, Anthropos, 1993.

Sharp, H., Spinoza and the Politics of Renaturalization, Chicago, University of Chicago Press, 2011.

Spinoza, B. de, Opera, (4 vols.), ed. de C. Gebhardt, Heidelberg, Carl Winters, 1972 ( $1^{\text {a }}$ edición, 1925$)$.

Spinoza, B. de, Ética, trad. Vidal Peña, Madrid, Editora Nacional, 1980.

Spinoza, B. de, Tratado teológico-político, trad. Atilano Domínguez, Madrid, Alianza, 1986.

Spinoza, B. de, Tratado político, trad. Atilano Domínguez, Madrid, Alianza, 1986.

Zourabichvili, F., "L'énigme de la 'multitude libre”, en Ch. Jaquet, P. Sévérac et A. Suhamy (dir.), La multitude libre. Nouvelles lectures du Traité politique, París, Éditions Amsterdam, 2008. 